\title{
ARTICLE \\ c-MYC responds to glucose deprivation in a cell-type-dependent manner
}

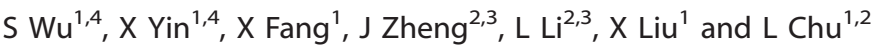

\begin{abstract}
Metabolic reprogramming supports cancer cells' demands for rapid proliferation and growth. Previous work shows that oncogenes, such as MYC, hypoxia-inducible factor 1 (HIF1), have a central role in driving metabolic reprogramming. A lot of metabolic enzymes, which are deregulated in most cancer cells, are the targets of these oncogenes. However, whether metabolic change affects these oncogenes is still unclear. Here we show that glucose deprivation (GD) affects c-MYC protein levels in a cell-type-dependent manner regardless of P53 mutation status. GD dephosphorylates and then decreases C-MYC protein stability through PI3K signaling pathway in HeLa cells, but not in MDA-MB-231 cells. Role of c-MYC in sensitivity of GD also varies with cell types. c-MYC-mediated glutamine metabolism partially improves the sensitivity of GD in MDA-MB-231 cells. Our results reveal that the heterogeneity of cancer cells in response to metabolic stress should be considered in metabolic therapy for cancer.
\end{abstract}

Cell Death Discovery (2015) 1, 15057; doi:10.1038/cddiscovery.2015.57; published online 23 November 2015

\section{INTRODUCTION}

Proliferating cells and most cancer cells produce energy and macromolecules through an unusual metabolic pathway compared with non-proliferating or differentiated cells. They metabolize glucose from oxidative phosphorylation to glycolysis regardless of the availability of oxygen, and this phenomenon is known as aerobic glycolysis or Warburg effect. ${ }^{1}$ Comparing with oxidative phosphorylation, glycolysis is a less efficient-way to consume glucose, at least in term of ATP production. One explanation is that a lot of intermediates are produced by glycolysis to meet the bioenergetic and biosynthetic demands of rapid proliferation. ${ }^{2}$ In addition, reduction of the demand of oxygen helps cancer cells survive in low-oxygen condition. ${ }^{3,4}$

A series of enzymes involved in glucose metabolism are responsible for the metabolic alterations during tumorigenesis, for example, glucose transporter 1 (GLUT1), ${ }^{5}$ phosphofructokinase (PFK), ${ }^{6}$ phosphoglycerate kinase 1 (PGK1), pyruvate kinase, muscle (PKM), lactate dehydrogenase A (LDHA). ${ }^{8}$ These genes are deregulated in most cancer cells. Most proliferating cancer cells highly express $M 2$ isoform of pyruvate kinase $M$ (PKM2) instead of PKM1 in normal differentiated cells. ${ }^{10}$ It is believed that low catalytic activity of PKM2 allows accumulation of glycolytic intermediates for macromolecular biosynthesis to increase cell proliferation and tumor growth. ${ }^{11,12}$ Phosphofructokinase/ fructose-2,6-bisphosphatase B3 gene (PFKFB3) is more selectively expressed in human cancers than other splice variants. ${ }^{13}$ PFKFB3 catalyzes a rate-limiting step of glycolysis with high kinase activity, resulting in promotion of glucose consumption and glycolytic flux. ${ }^{14}$ LDHA promotes glycolysis and tumor cell growth by regulating the intracellular $\mathrm{NADH} / \mathrm{NAD}^{+}$redox homeostasis. $^{15,16}$ Excretion of lactate to extracellular matrix changes the microenvironment and promotes tumor migration and invasion. ${ }^{17}$
Deregulation of oncogenes, tumor suppressors or related signaling pathways drives the metabolic changes. A large amount of metabolic enzymes are regulated by oncogene c-MYC, HIF1a and KRAS, tumor suppressor gene P53 or PI3K/AKT ${ }^{18}$ and AMPK signaling pathways. ${ }^{19}$ For instance, c-MYC not only regulates expression of hexokinase 1 (HK1), PFK, PDK1 and LDHA, ${ }^{19}$ but also promotes mitochondrial gene expression and mitochondrial biogenesis. ${ }^{20}$ Gao et.al. reported that c-MYC promotes glutamine metabolism by enhancing the expression of glutaminase (GLS). ${ }^{21}$ Glutamine is important for cell proliferation as a nitrogen donor and carbon source in glucose-independent way. ${ }^{22}$ P53 expression also controls a large number of metabolic genes including GLUT1, ${ }^{23}$ TP53-induced glycolysis and apoptosis regulator (TIGAR), ${ }^{24}$ synthesis of cytochrome C oxidase 2 (SCO2). ${ }^{25}$

However, cancer cell metabolism reprogramming is not only the result of deregulation of metabolic enzymes, oncogenes or tumor suppressor genes. Metabolic alteration might be an actively adaptive process. Glycolysis provides advantages for cancer cells to survive in the microenvironment with low oxygen and nutrient. ${ }^{26}$ Metabolic changes are not only the downstream of oncogenic pathways, but also an upstream event that regulates the signaling pathways. Numerous studies have shown that $\mathrm{PI} 3 \mathrm{~K} /$ $\mathrm{AKT}^{27,28} \mathrm{AMPK}^{29,30}$ and mTOR signaling pathways ${ }^{31,32}$ are activated upon glucose deprivation. In addition, glucose controls the intracellular acetylation level of proteins, including mitochondrial proteins, ${ }^{33}$ metabolic enzymes ${ }^{11,34}$ and histones. ${ }^{35}$

In the present study, we assessed the effect of glucose deprivation (GD) on c-MYC protein in several cancer cell lines. We found that GD affected c-MYC protein levels in a cell-typedependent manner. GD increased c-MYC transcription in both HeLa cells and MDA-MB-231 cells, but decreased c-MYC protein stability only in HeLa cells. PI3K and SIRT1 were involved in the regulation of c-MYC protein stability in HeLa cells. In addition, we showed that c-MYC played different role in the sensitivity to GD in

\footnotetext{
'State Key Laboratory of Cell Biology, Institute of Biochemistry and Cell Biology, Shanghai Institutes for Biological Sciences, Chinese Academy of Sciences, 320 Yue-Yang Road, Shanghai 200031, China; ${ }^{2}$ Jiangsu Center for the Collaboration and Innovation of Cancer Biotherapy, Cancer Institute, Xuzhou Medical College, Xuzhou, Jiangsu 221002, China and ${ }^{3}$ Center of Clinical Oncology, Affiliated Hospital of Xuzhou Medical College, Xuzhou, Jiangsu 221002, China.

Correspondence: X Liu or L Chu (xyliu@sibcb.ac.cn or Ichu@sibcb.ac.cn)

${ }^{4}$ These authors contributed equally to this work.

Received 8 September 2015; revised 14 October 2015; accepted 21 October 2015; Edited EA Sayan
} 
HeLa cells and MDA-MB-231 cells. Resistance of GD in MDAMB-231 cells was partially associated with c-MYC-mediated glutamine metabolism. Our results provide evidence about the heterogeneity of cancer cells to GD and suggest that targeting glucose metabolism for cancer therapy should be discriminately evaluated.

\section{RESULTS}

Glucose deprivation affects c-MYC protein levels in a cell-type-dependent manner

Previous work showed that oncogenes, such as c-MYC, drive the metabolic reprogramming. ${ }^{36}$ To determine whether metabolic change affects c-MYC, different cell lines were subjected to glucose deprivation (GD). Phosphorylation of AMPK was used as an indicator of the effect of GD. GD decreased c-MYC protein levels in HEK293T and HeLa cells, but increased c-MYC protein levels in MDA-MB-231 cells (Figures 1a-c). Intriguingly, GD elevated c-MYC mRNA levels in HeLa cells and to a great extent in MDA-MB-231 cells (Figures 1d and e). PDK1, LDHA and GLUT1 were also changed in response to GD. These data provide evidence of the mutual regulation between glucose metabolism and the metabolic-related genes.

Glucose deprivation decreases c-MYC protein stability in HeLa cells but not in MDA-MB-231 cells

We first investigated why c-MYC protein levels were decreased even when the mRNA levels were elevated in response to GD in HeLa cells. HeLa and MDA-MB-231 cells were treated with protein synthesis inhibitor cycloheximide (CHX) or proteasomal inhibitor MG-132, respectively. The half-life of c-MYC is short and 12-h treatment of $\mathrm{CHX}$ completely depleted c-MYC protein in both HeLa and MDA-MB-231 cells. On the contrary, MG-132 significantly induced accumulation of c-MYC in both cells and blocked GD-mediated decrease of c-MYC in HeLa cells (Figure 2a). GD also increased the ubiquitination of c-MYC in the presence of MG-132 (Figure 2b). We used lysosomal protease inhibitors bafilomycin A1, Leupeptin and 3-MA to exclude the possibility that c-MYC was degraded through autophagy in HeLa cells under GD condition (Figure 2c). CHX chase experiment indicated that the half-life of c-MYC in HeLa cells was decreased in the absence of glucose (Figure $2 \mathrm{~d}$ ).

To evaluate the effect of GD on c-MYC protein stability, cells ectopically expressing c-MYC were treated with MG-132 under GD condition. Comparing with HeLa cells, exogenous c-MYC in MDA-MB-231 cells was not affected after GD treatment (Figures $2 e$ and $f$ ), indicating that GD does not affect c-MYC protein stability in MDA-MB-231 cells. In addition, ectopically expressing C-MYC driven by CMV promoter also excluded the possibility that c-MYC was controlled by IRES-dependent translation. ${ }^{37}$ These data explain that c-MYC protein levels were accumulated in MDA-MB-231 cells but not in HeLa cells in response to $\mathrm{GD}$.

SKP2 and FBXW7 are two main E3 ubiquitin ligases of c-MYC. $^{38,39}$ However, overexpression of SKP2 or an F-box deleted dominant negative mutant SKP2 $(\triangle \mathrm{F}-\text { box })^{40}$ did not affect GD-mediated degradation of c-MYC in HeLa cells (Figure $2 \mathrm{~g}$ ). c-MYC is degraded by FBXW7 in a phosphorylation-dependent manner. ${ }^{41}$ Phosphorylation of Thr58 and Ser62 was not affected in response to GD (Figure $2 \mathrm{~h}$ ) and overexpression of FBXW7 also had no effect on c-MYC protein regardless of glucose (Figure 2i). This implies that other E3 ubiquitin ligase may be responsible for GD-induced degradation of c-MYC.

Cell-type-dependent response of c-MYC to GD is not dependent on P53

To figure out how c-MYC protein stability vary with cell types in response to GD, c-MYC protein expressions were examined in several cell lines (Table 1). TP53, Ras and PIK3CA have important role in glucose metabolism, ${ }^{12,42,43}$ and are commonly mutated in cancers. ${ }^{44-47}$ We summarized the mutations in these cell lines by referring to Catalogue of Somatic Mutation in Cancer (COSMIC), and noticed that c-MYC protein decreased in four cell lines with wild-type P53 (HEK293T, HeLa, MCF7, HCT116), and increased in majority cell lines with mutated P53 or P53-null after GD treatment (Table 1).
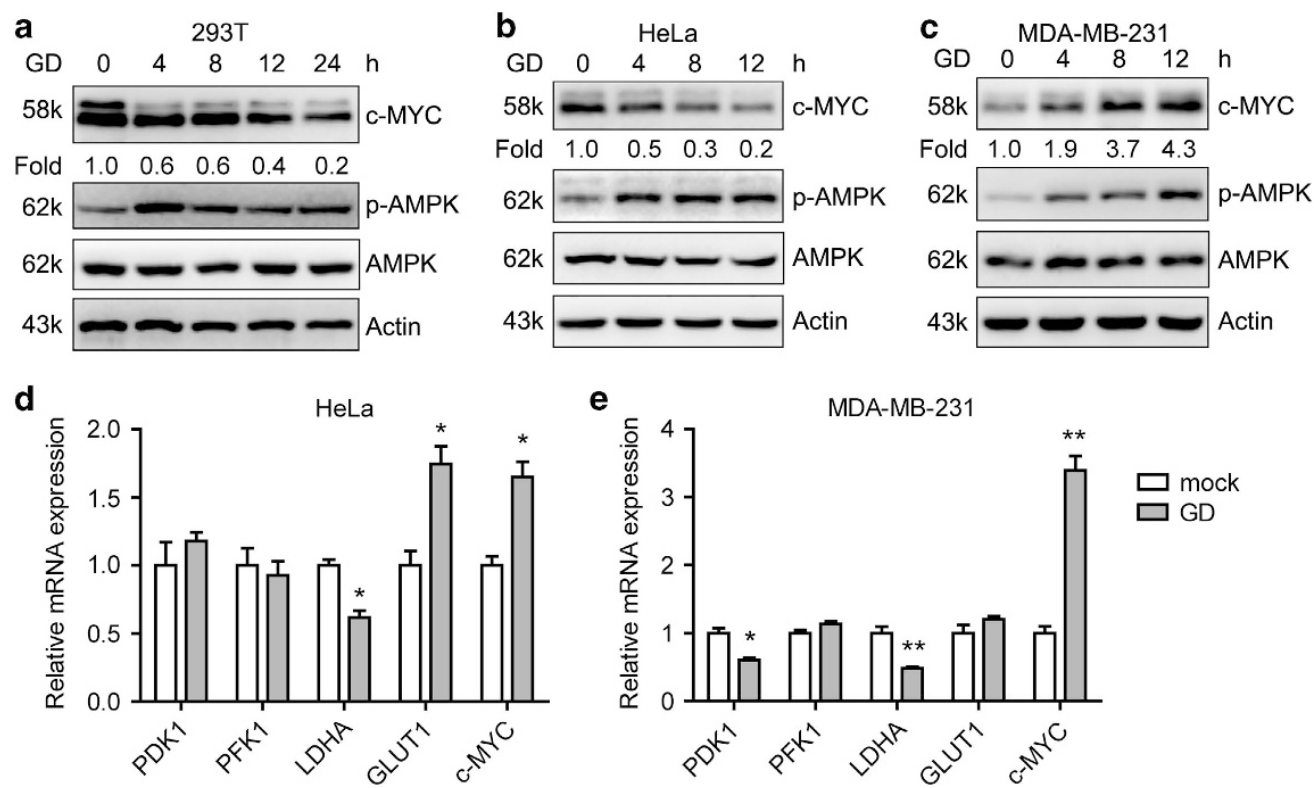

Figure 1. Glucose deprivation differentially affects c-MYC protein levels in different cells. (a-c) Western blot detection of c-MYC levels in HEK293T (a), HeLa (b) and MDA-MB-231 (c) cells exposed to GD (0.5 mM) for the indicated intervals. (d and e) Quantitative RT-PCR detection of PDK1, PFK1, LDHA, GLUT1 and c-MYC levels in HeLa (d) and MDA-MB-231 (e) cells under GD condition for $12 \mathrm{~h}$. Values represent the relative induction normalized to $18 \mathrm{~S} .{ }^{*} P<0.05,{ }^{* *} P<0.01$ versus mock. Data of three independent experiments are shown. 
a

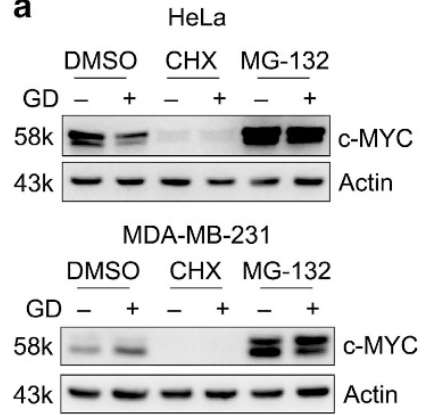

b C-MYC-Flag +++++

HA-Ub -++++

MG-132 - - + + +

$\mathrm{GD}-\ldots+\ldots+$

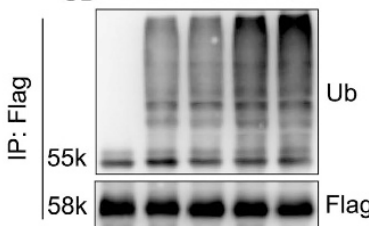

C DMSO Baf Leupeptin 3-MA

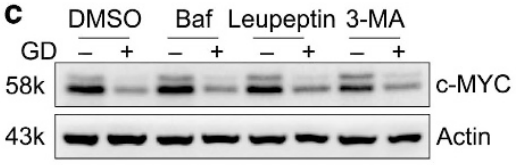

d

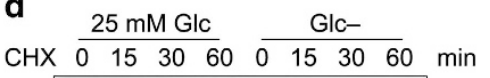

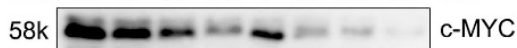

$43 \mathrm{k}$
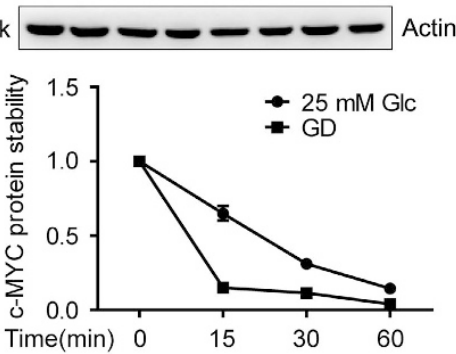

e

HeLa

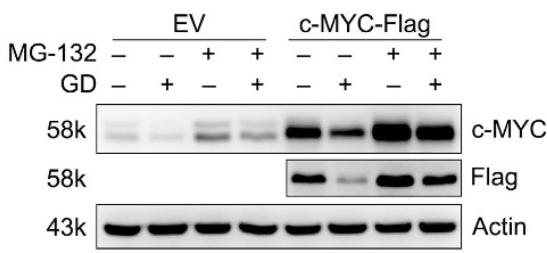

f
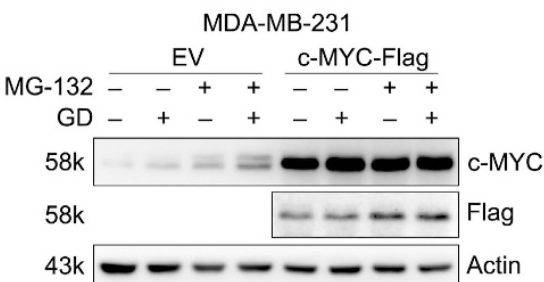

g

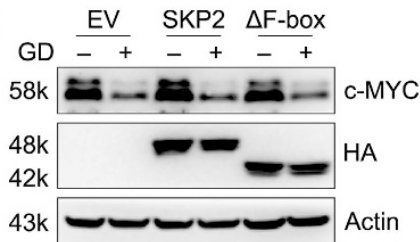

h
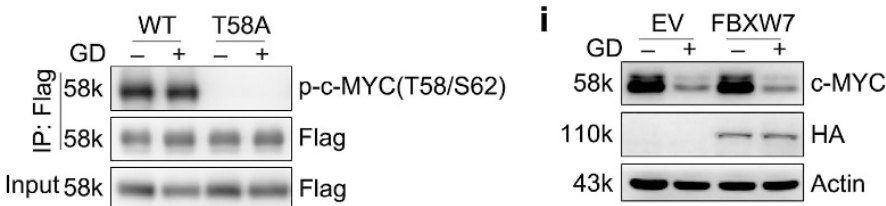

Figure 2. Glucose deprivation differentially affects c-MYC protein stability in HeLa and MDA-MB-231 cells. (a) Western blot detection of c-MYC in HeLa and MDA-MB-231 cells treated with CHX $(0.1 \mathrm{mM})$ and MG-132 $(10 \mu \mathrm{M})$ in the presence or absence of $25 \mathrm{mM}$ glucose for $12 \mathrm{~h}$. (b) HEK293T cells cotransfected with c-MYC-Flag and HA-Ub were treated with MG-132 in the presence or absence of glucose for $12 \mathrm{~h}$. Ubiquitination of c-MYC was determined. (c) Western blot detection of c-MYC in HeLa cells treated with Bafilomycin A1 (Baf) (500 nM), Leupeptin $(10 \mu \mathrm{g} / \mathrm{ml})$ or $3-\mathrm{MA}(1 \mathrm{mM})$ in the presence or absence of glucose for $12 \mathrm{~h}$. (d) HeLa cells were treated with CHX for the indicated time in the presence or absence of glucose. Representative immunoblots of c-MYC in three independent experiments were shown. Bottom, quantification of the c-MYC levels was shown. (e and f) HeLa (e) and MDA-MB-231 (f) stable cells ectopically expressing c-MYC-Flag were treated with MG-132 in the presence or absence of glucose. Exogenous c-MYC stability was examined. (g) Western blot detection of c-MYC in HeLa stable cells expressing WT HA-SKP2 or HA-tagged dominant negative mutant HA-SKP2( $\Delta$ F-box) under GD condition for $12 \mathrm{~h}$. (h) HEK293T cells were transfected with WT-c-MYC-Flag or c-MYC(T58A)-Flag. Cell lysates were subjected to immunoprecipitation and phosphorylation of c-MYC was examined. (i) Western blot detection of c-MYC in HeLa stable cells expressing FBXW7 treated as in $\mathbf{g}$.

Table 1. Summary of c-MYC protein level changes under GD condition for $12 \mathrm{~h}$ as measured by Western blot

\begin{tabular}{lllll}
\hline Cell line & C-myc change & TP53 & PIK3CA & Ras \\
\hline 293T & Decrease & WT & WT & WT \\
HeLa & Decrease & WT & WT & WT \\
MDA-MB-231 & Increase & R280K & WT & G13D \\
MCF7 & Decrease & WT & E545K & WT \\
HCT116 & Decrease & WT & H1047R & G13D \\
HT-29 & Increase & R273H & P449T & WT \\
SW620 & Increase & R273H & WT & G12V \\
Hep3B & Increase & null & WT & WT \\
H1299 & Increase & null & WT & WT \\
SK-OV-3 & Increase & S90fs*33 & H1047R & WT \\
T-24 & Decrease & Y126* & WT & WT \\
K562 & Decrease & Q136fs*13 & WT & WT \\
A549 & Increase & WT & WT & G12S \\
BxPC-3 & Increase & Y220C & WT & WT \\
PANC-1 & Increase & R273H & WT & G12D \\
PLC & Increase & R249S & WT & WT \\
HuH-7 & Increase & Y220C & WT & WT \\
\hline
\end{tabular}

P53 was reported functionally inactive in HeLa cells because of expression of human papiloma virus $\mathrm{E} 6 .{ }^{48}$ To detect the role of P53 in GD-mediated degradation of c-MYC, we knocked out P53 in HeLa cell line using CRISPR/Cas9 system. c-MYC protein levels in P53 KO cells were significantly decreased compared with control cells, and were further declined under GD condition (Figure 3a). Overexpression of mutant P53(R280K) in HeLa cells did not reverse the decreased expression of c-MYC caused by GD (Figure 3b). In addition, c-MYC protein levels were still upregulated after GD in WT-P53 overexpression MDA-MB-231 cells (Figure 3c). Ectopically expressing of WT-P53 or mutant P53(R280K) in the P53-null Hep3B cell line did not reverse the increased expression of c-MYC caused by GD (Figures $3 d$ and e). These data indicate that cell-typedependent different response of c-MYC to GD is not caused by P53 mutation.

Glucose deprivation increases c-MYC transcription partially through ERK signaling pathway

Figures $1 \mathrm{~d}$ and e showed that c-MYC transcription was elevated in both HeLa and MDA-MB-231 cells. Given that GD affects several 

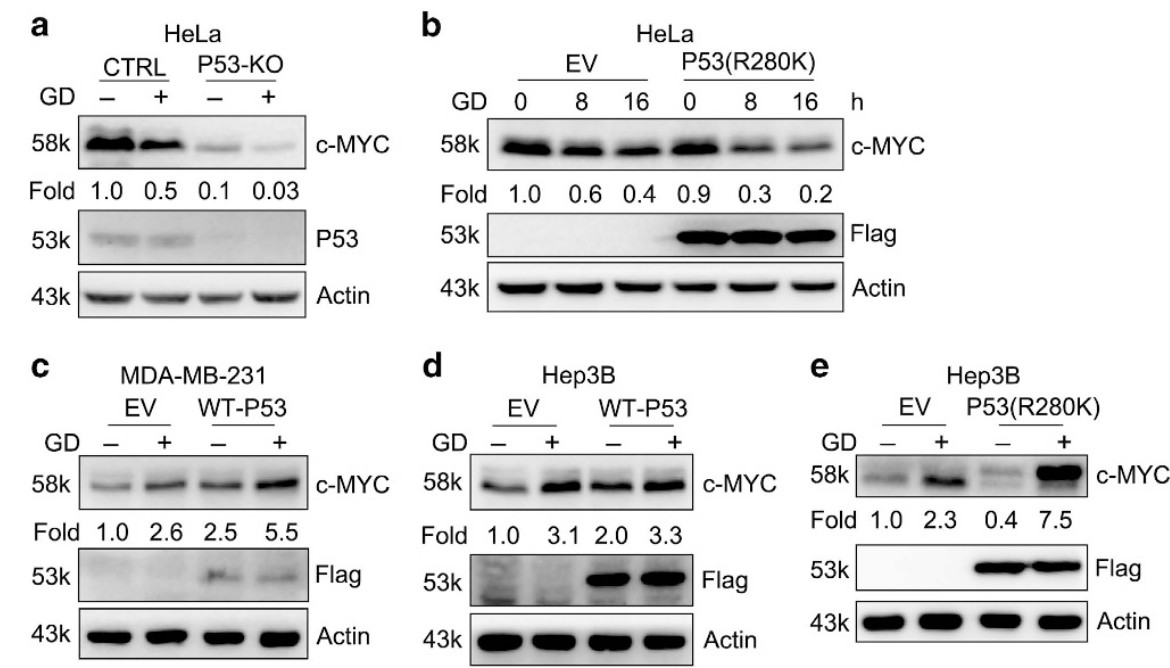

Figure 3. Cell-type-dependent response of c-MYC to GD is not caused by p53 mutation. (a) Western blot detection of c-MYC in HeLa control or P53 KO cells under GD condition for $12 \mathrm{~h}$. (b) Western blot detection of c-MYC in HeLa stable cells expressing P53(R280K) under GD condition for the indicated intervals. (c-e) Western blot detection of c-MYC in MDA-MB-231 stable cells expressing WT-P53 (c), Hep3B stable cells expressing WT-P53 (d) or P53(R280K) (e) under GD condition for $12 \mathrm{~h}$.

signaling pathways such as $\mathrm{p} 38 / \mathrm{MAPK}^{49}{ }^{\mathrm{PI} 3 \mathrm{~K} / \mathrm{AKT}},{ }^{50} \mathrm{ERK}^{51}$ and AMPK, ${ }^{52}$ chemical inhibitors were applied to examine which pathway is involved in GD-mediated elevation of c-MYC transcription. Phosphorylation specific antibodies p-p38, p-AKT, p-ERK and p-ACC were used as indicators to show the effects of the inhibitors. We observed that p38/MAPK, PI3K/AKT, ERK and AMPK pathways were all activated after GD and only ERK inhibitor U0126 blocked both mRNA and protein levels in HeLa and MDA-MB-231 cells whether glucose existed or not (Figure 4). However, c-MYC mRNA and protein levels were still elevated in MDA-MB-231 cells and reduced in HeLa cells after GD when ERK signaling was inhibited by U0126. These data indicate that ERK pathway is partially involved in GD-mediated c-MYC transcription activation in both HeLa and MDA-MB-231 cells.

$\mathrm{PI} 3 \mathrm{~K}$, but not AKT, is involved in GD-mediated decrease of c-MYC protein stability in HeLa cells

Meanwhile, we found that degradation of c-MYC under GD condition in HeLa cells were prevented by $\mathrm{PI} 3 \mathrm{~K}$ inhibitor Wortmannin and SIRT inhibitor NAM (Figure 4e). Another PI3K inhibitor LY294002 showed similar effect as Wortmannin (Figure 5a). PI3Ks are composed of a catalytic subunit (p110) and a regulatory subunit (p85). ${ }^{53}$ To specifically confirm the role of PI3Ks in GD-mediated degradation of c-MYC in HeLa cells, we constructed a dominant negative mutant of p85 (p85-DN), which lose the regulatory activity of catalytic subunit p110. ${ }^{54}$ p85-DN prevented GD-mediated degradation of c-MYC protein in consistent with the effect of Wortmannin and LY294002 (Figure 5b).

AKT is the main target of PI3K, and is activated by growth factor in a PI3K-dependent way. ${ }^{55}$ Activated AKT phosphorylates and inactivates glycogen synthase kinase 3 (GSK3), and then prevents GSK3 $\beta$-mediated phosphorylation and degradation of downstream targets such as C-MYC ${ }^{56}$ and cyclin D1. ${ }^{57}$ We found that both AKT inhibitor MK-2206 and GSK3 $\beta$ inhibitor SB-216763 had no significant effect on GD-mediated degradation of c-MYC (Figure 5c). Inhibition of AKT by a dominant negative mutant AKTDN or activation of AKT by a constitutively active mutant AKT-CA ${ }^{58}$ had no distinct effect on c-MYC protein levels as similar as p85-DN (Figure $5 \mathrm{~d}$ ). These results demonstrate that GD induces c-MYC degradation through a PI3K-, but not AKT-, dependent way.
Both PI3K and SIRT1 regulate c-MYC phosphorylation and the following protein stability under GD condition

The above data showed that Wortmannin and NAM abolished GD-mediated degradation of c-MYC. To investigate how PI3K and SIRT affect c-MYC protein stability, we examined the phosphorylation of c-MYC treated with NAM or Wortmannin under GD condition. Results showed that GD decreased c-MYC phosphorylation. Both inhibitors, especially Wortmannin, significantly blocked the GD-mediated dephosphorylation of c-MYC (Figure 5e). Considering that NAM is a SIRTs inhibitor, we supposed that the effect of NAM on c-MYC phosphorylation is indirect.

We further found that SIRT1 activator SRT1720 could mimic the effect of GD on c-MYC protein levels (Figure 5f). However, SIRT2 specific inhibitor AGK2 failed to block GD-mediated degradation of c-MYC protein (Figure $5 \mathrm{~g}$ ). This indicates that SIRT1 is involved in GD-mediated degradation of c-MYC in HeLa cells.

To further confirm the function of SIRT1, we cotransfected SIRT1 or SIRT2 with c-MYC. SIRT1 effectively decreased c-MYC phosphorylation and protein level, whereas SIRT2 showed only minor effect on c-MYC phosphorylation (Figure 5h). In addition, GD-induced dephosphorylation of c-MYC was markedly enhanced by overexpression of SIRT1 and inhibited by kinase-dead mutant SIRT1-HY (Figure 5i). ${ }^{59}$ Collectively, these data indicate that both PI3K and SIRT1 regulate GD-mediated dephosphorylation and degradation of c-MYC.

c-MYC-mediated glutamine metabolism is involved in the resistance to GD in MDA-MB-231 cells

c-MYC has been reported to affect cell viability under GD condition $^{60,61}$ and this effect might vary with cell type. ${ }^{62}$ We found that HeLa and MDA-MB-231 cells showed distinct response to glucose or glutamine deprivation (Figure 6a). Overexpression of c-MYC in HeLa cells increased cell viability in normal medium, but had negligible effect on cell viability under GD condition (Figure 6b). By contrast, overexpression of a transactivation domain-deleted mutant $\mathrm{MYC}(\Delta \mathrm{N})^{63}$ markedly sensitized MDAMB-231 cells to GD (Figure $6 c$ ). These findings suggest that c-MYC might exert different role in HeLa and MDA-MB-231 cells under GD condition.

Given that c-MYC enhances glutamine metabolism reprogramming, ${ }^{64,65}$ we speculate that c-MYC promotes glutamine 
a

MDA-MB-231

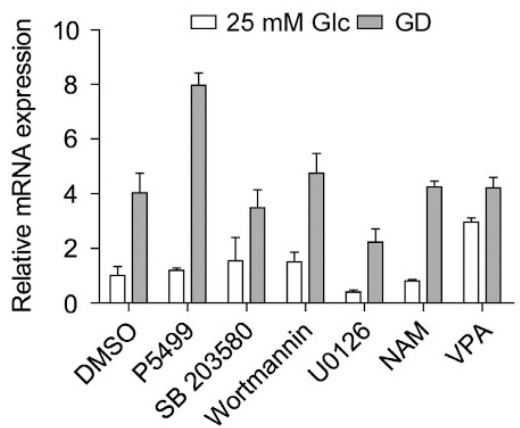

C

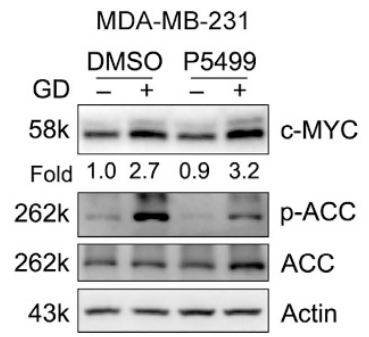

c

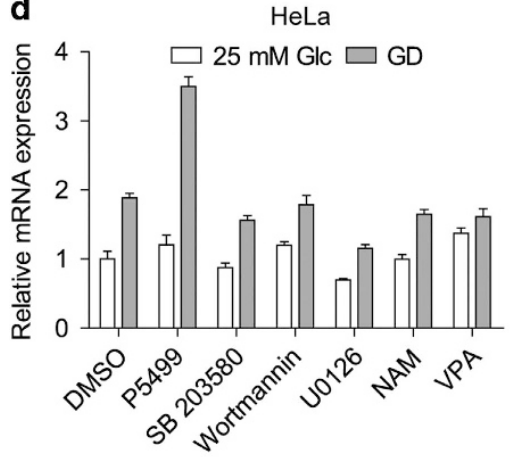

f

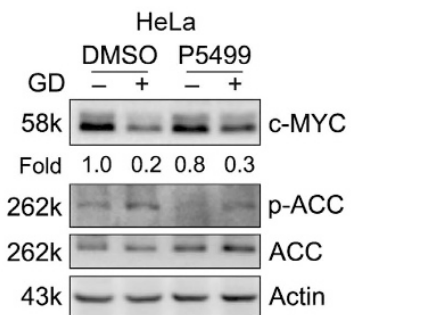

b $\quad$ MDA-MB-231

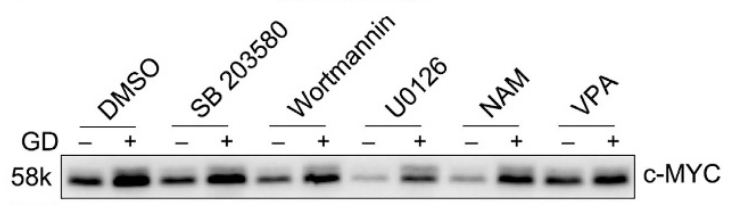

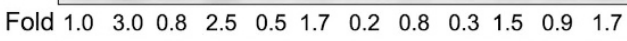

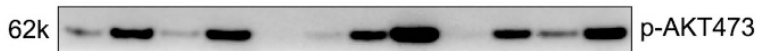

$62 \mathrm{k}-\ldots-\cdots-\cdots$ AKT

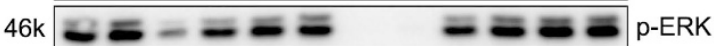

$46 \mathrm{k}-\ldots-\ldots-\ldots-\ldots \mathrm{ERK}$

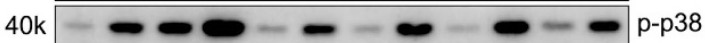

40k

$43 \mathrm{k}-\infty-\infty-1--0$ Actin

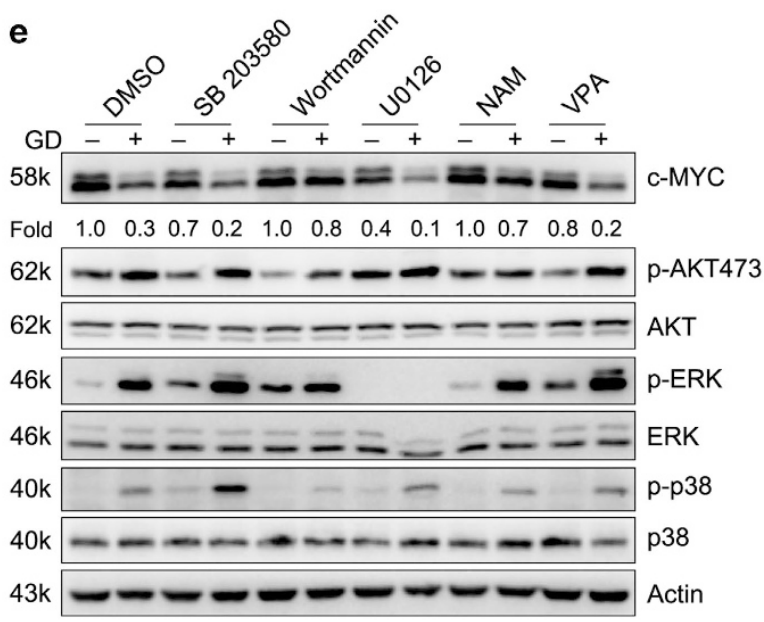

Figure 4. Glucose deprivation increases c-MYC transcription partially through ERK signaling pathway in MDA-MB-231 cells. Quantitative RT-PCR (a) and Western blot (b and $\mathbf{c}$ ) detection of c-MYC in MDA-MB-231 cells treated with different chemical inhibitors for $12 \mathrm{~h}$ in the medium with or without glucose. The indicated chemical inhibitors are AMPK inhibitor P5499 (10 $\mu \mathrm{M})$, p38/MAPK inhibitor SB 203580 (10 $\mu$ M), PI3K/AKT inhibitor Wortmannin $(10 \mu \mathrm{M})$, ERK/MEK inhibitor U0126 (10 $\mu \mathrm{M})$, SIRT inhibitor NAM (1 mM) and HDAC inhibitor VPA (1 mM). (d-f) HeLa cells were treated and detected as that of MDA-MB-231 in a-c. Quantitative RT-PCR values were relative to the DMSO group with 25 mM Glc and normalized to $18 \mathrm{~S}$. Data of three independent experiments are shown.

metabolism in MDA-MB-231 cell. To test this hypothesis, we performed luciferase assay to examine the effect of GD on the $3^{\prime}$-UTR reporter activity of GLS1, which is the target of c-MYC and responsible for glutamine metabolism. ${ }^{21}$ Luciferase assay and immunoblot showed that GD decreased GLS1 3'-UTR activity and protein levels in HeLa cells but displayed an opposite effect in MDA-MB-231 cells (Figures 6d-f). In addition, both GLS1 inhibitor CB-839 (Figure 6g) and shRNA interference of GLS1 (Figure 6h) sensitized MDA-MB-231 cells to GD. Collectively, these results demonstrate that resistance to GD in MDA-MB-231 cells is partially due to glutamine metabolism driven by c-MYC.

\section{DISCUSSION}

Cancer cells need large amount of energy and intermediates to fuel their rapid proliferation and growth. To meet the demand, cancer cells experience metabolic reprogramming. This change is thought to result from deregulation of oncogenes or tumor suppressor genes. ${ }^{36,66,67}$ In this study, we showed that GD could alter oncogene c-MYC levels in different cancer cell lines. Our present data unveil a mutual regulation between metabolism and oncogenes or tumor suppressor genes.

The extremely different background of each cell line makes it difficult to identify which molecule determines the change of 
a

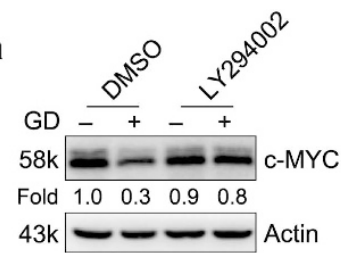

b

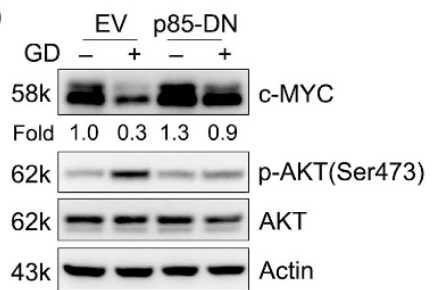

c

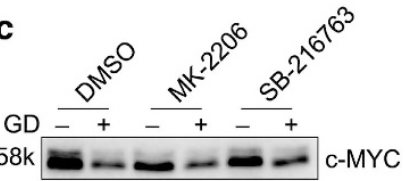

Fold $\begin{array}{llllll}1.0 & 0.2 & 0.7 & 0.2 & 0.8 & 0.3\end{array}$

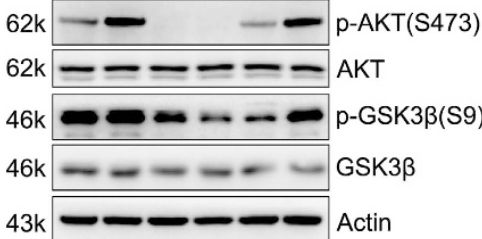

d

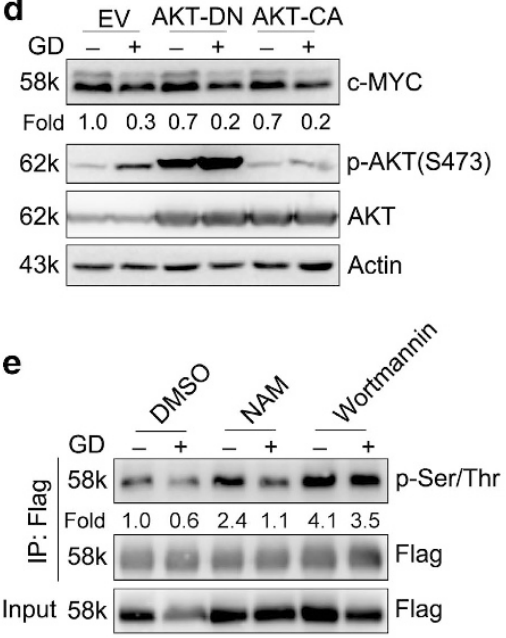

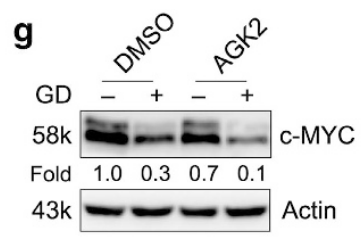

h

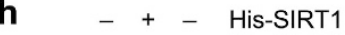

$-\quad+$ His-SIRT2

+++ c-MYC-Flag

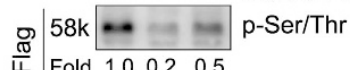

i் $58 \mathrm{k}=\mathrm{m}=\mathrm{Flag}$

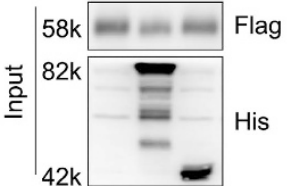

f

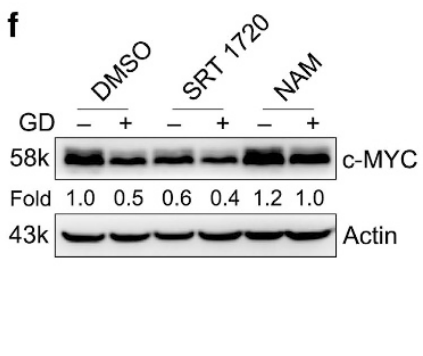

I

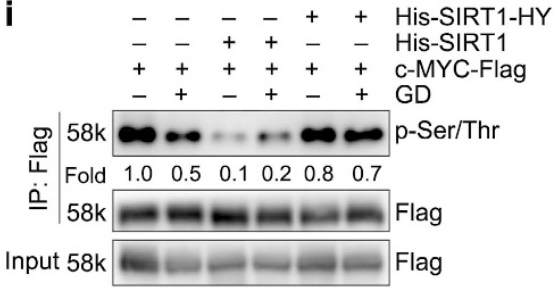

Figure 5. Both SIRT1 and PI3K regulates c-MYC phosphorylation and the following protein stability under GD condition. (a) Western blot detection of c-MYC in HeLa cells treated with LY294002 (10 $\mu \mathrm{M})$ under GD condition for $12 \mathrm{~h}$. (b) Western blot detection of c-MYC in HeLa stable cells expressing dominant negative mutant p85-DN under GD condition for $12 \mathrm{~h}$. (c) Western blot detection of c-MYC in HeLa cells treated with MK-2206 $(10 \mu \mathrm{M})$ or SB-216763 $(10 \mu \mathrm{M})$ under GD condition for $12 \mathrm{~h}$. (d) Western blot detection of c-MYC in HeLa stable cells expressing constitutively active mutant AKT-CA or dominant negative mutant AKT-DN under GD condition for $12 \mathrm{~h}$. (e) Effects of NAM and Wortmannin on phosphorylated Ser/Thr of c-MYC immunoprecipitated from HEK293T cell lysates under GD condition. (f and $\mathbf{g}$ ) Western blot detection of c-MYC in HeLa cells treated with SRT1720 $(10 \mu \mathrm{M})(\mathbf{f})$ or AGK2 $(10 \mu \mathrm{M})(\mathbf{g})$ under GD condition for $12 \mathrm{~h}$. NAM was used as a positive control. (h) MYC-Flag was cotransfected with His-SIRT1 or His-SIRT2 into HEK293T cells. Phosphorylated Ser/Thr of immunoprecipitated c-MYC was examined. (i) MYC-Flag was cotransfected with His-SIRT1 or kinase-dead His-SIRT1-HY into HEK293T cells and maintained under 25 mM glucose or GD condition for $12 \mathrm{~h}$. Phosphorylated Ser/Thr of immunoprecipitated c-MYC was examined.

c-MYC under GD condition. A feasible way is to expand the number of cell lines for detection. We examined c-MYC expression in 17 cell lines and analyzed some key point mutations related to glucose metabolism. It seems that there is a close correlation between P53 mutation and c-MYC change in response to GD (Table 1). However, our data indicated that P53 cannot determine the different response of c-MYC to GD in HeLa (WT P53), MDAMB-231 (mutant P53) and Hep3B (P53 null) cells (Figure 3). So far, we cannot confirm that P53 is responsible for GD-mediated variant c-MYC change in other cell lines. Further studies are required to clarify the molecular regulators.

We found that GD increased c-MYC transcription levels partially through ERK signaling pathway (Figure 4). This is consistent with previous data. ${ }^{68}$ Besides ERK, Blackburn et al. reported that JNK1 is also involved in GD-induced increase of c-MYC transcription. In any way, c-MYC transcription in both HeLa and MDA-MB-231 cells are elevated in response to GD. Here our study focused on the different response of c-MYC under GD condition between HeLa and MDA-MB-231 cells. This is the reason that we pay much attention to c-MYC protein levels other than transcription levels. Although we demonstrate that PI3K and SIRT1 could block GD-mediated degradation of c-MYC, the effect may not be direct, because PIK3CA localizes in the cytoplasm and membrane, while c-MYC is mainly accumulated in the nucleus. SIRT1 might affect c-MYC phosphorylation and degradation through deacetylation.
GD differentially affects c-MYC protein stability in HeLa and MDA-MB-231 cells (Figures 2e and f). There are three possibilities. First, mutation of c-MYC inhibits its degradation. Second, specific E3 ubiquitin ligase, which is required for c-MYC degradation, loses its function. Third, post-translational modifications, especially phosphorylation, ${ }^{41}$ have important roles in C-MYC proteins stability. ${ }^{69}$ Deregulation of post-translational modification may inhibit c-MYC following degradation. We noticed that c-MYC is not mutated in HeLa and MDA-MB-231 cells and the known c-MYC E3 ubiquitin ligases, such as SKP2 and FBXW7, are normal in both cells. So the most possible reason is that there are other different factors between HeLa and MDA-MB-231 cells that affect the phosphorylation of c-MYC.

Several factors are reported to be responsible for the sensitivity to GD in different cancer cells. ${ }^{68,70,71}$ We found that c-MYCmediated glutamine metabolism enhances the tolerance to GD in MDA-MB-231, but not in HeLa cells (Figure 6). This is consistent with previous data that glucose metabolism is heterogeneous in different cells. ${ }^{62,72}$ Our data provide evidence to show the role of c-MYC in the transition from glucose metabolism to glutamine metabolism under GD condition.

Targeting cancer cell metabolism is a promising way for cancer therapy. An in-depth understanding of metabolic regulation in cancer cells will provide new insight for effective therapies. Our results suggest that the heterogeneity should be considered in metabolic cancer therapy targeting glucose metabolism. 

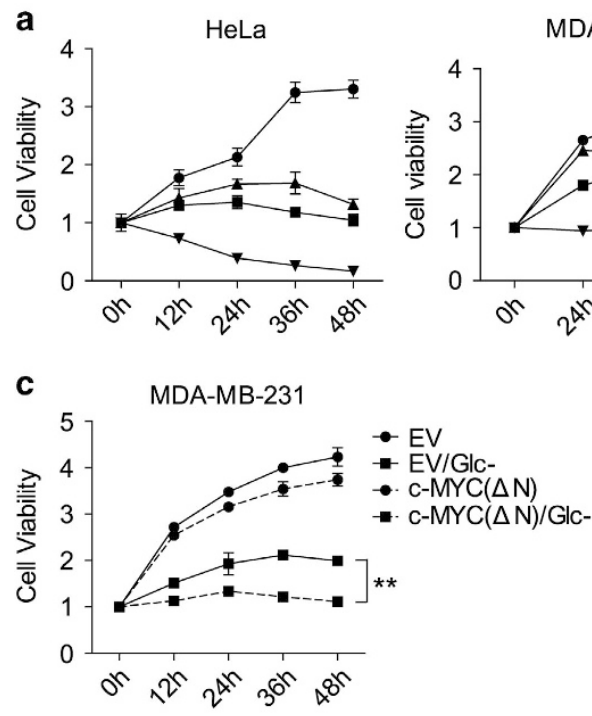

e
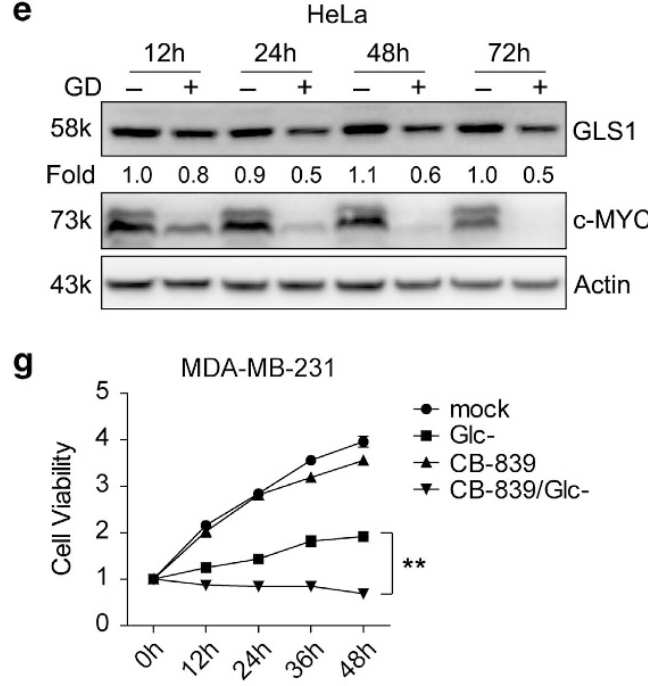

DA-MB-231

- mock

Glc-

- Glu- b

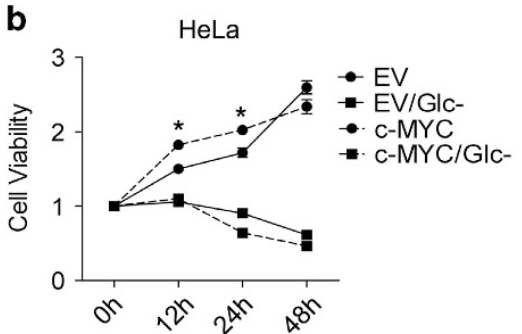

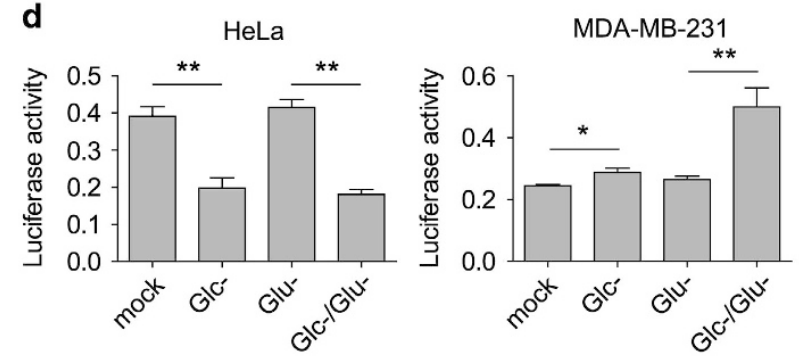

f
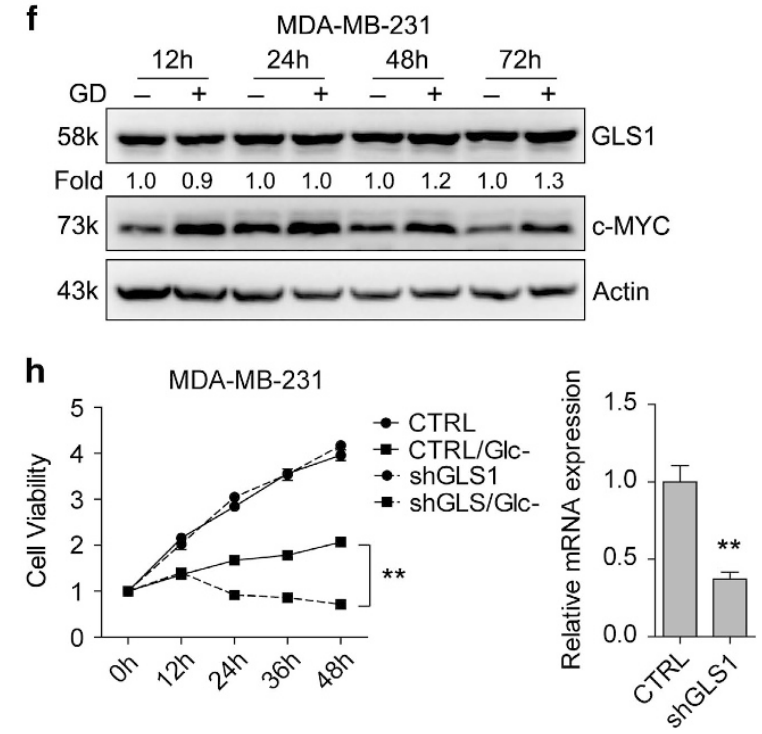

Figure 6. c-MYC-mediated glutamine metabolism is involved in the resistance to GD in MDA-MB-231 cells. (a) HeLa and MDA-MB-231 cells were maintained under the indicated medium for different intervals. Cell viabilities were examined by MTT assay. (b) HeLa stable cells expressing MYC were maintained under GD condition for different intervals and cell viabilities were examined by MTT. (c) MDA-MB-231 stable cells expressing c-MYC $(\Delta N)$ were treated as in b. (d) GLS1-3'-UTR was transfected into HeLa or MDA-MB-231 cells and maintained under the indicated medium for $36 \mathrm{~h}$. Luciferase activities were examined. ${ }^{*} P<0.05,{ }^{*} P<0.01$. (e and f) Western blot detection of GLS1 and c-MYC in HeLa (e) and MDA-MB-231 (f) cells under GD condition for different intervals. (g) MDA-MB-231 cells were treated with CB-839 (10 $\mu$ M) under GD condition for different intervals and cell viabilities were examined by MTT. (h) MDA-MB-231 stable cells infected with lenti-shGLS1 were treated as in (b). (Right) Examination of GLS1 knockdown efficiency by quantitative RT-PCR. Values are normalized to $18 \mathrm{~S}$ and relative to control group. MTT in ( $\mathbf{a}-\mathbf{c}, \mathbf{g}$ and $\mathbf{h}$ ) were repeated three times, and values are shown as fold changes versus $0 \mathrm{~h}$ group.

Change of c-MYC might be thought as an indicator of choosing targeting glucose metabolism or a combination of targeting glucose and glutamine metabolism.

\section{MATERIALS AND METHODS}

\section{Cell culture and reagents}

HeLa cell was cultured with DMEM (Invitrogen, CA, USA) supplemented with $10 \%$ fetal bovine serum (Biochrom, Berlin, Germany). MDA-MB-231 cell was cultured with Leibovitz's L-15 (Invitrogen) supplemented with 10\% fetal bovine serum. All the other cells were maintained following the ATCC guideline.

DMEM (no glucose), DMEM (no glutamine) and DMEM (no glucose, no glutamine) were purchased from Life Technologies (Carlsbad, CA, USA). Anti-c-MYC antibody was purchased from Abcam (Cambridge, MA, USA).
Anti-GLUT1 (H-43), Ub (P4D1) and P53 (Pab 1801) antibodies were purchased from Santa Cruz Biotechnology (Dallas, TX, USA). Anti-Flag, His, $\mathrm{HA}$ and Actin antibodies were purchased from Abmart (Shanghai, China). Anti-p-AKT (Ser473), AKT, p-GSK3 $\beta$ (Ser9), GSK3 $\beta$, p-AMPK(Thr172), AMPK, p-ACC(Ser79), ACC, p-p38(Thr180/Tyr182), p38, p-Ser/Thr, p-ERK1/2 (Thr202/Tyr204) and ERK antibodies were purchased from Cell Signaling Technology (Danvers, MA, USA). Anti-c-MYC(p-Thr58/Ser62) antibody was purchased from GeneTex (Irvine, CA, USA). Anti-GLS antibody was purchased from ABGENT (San Diego, CA, USA).

Chemical inhibitors: cycloheximide, bafilomycin A1, 3-MA and SB-216763 were purchased from Sigma (St. Louis, MO, USA). Leupeptin was purchased from Amresco (Solon, OH, USA). MG-132, Wortmannin, P5499, MK-2206, SRT1720, AGK2 and CB-839 were purchased from Selleck (Houston, TX, USA). VPA was purchased from Millipore (Billerica, MA, USA). SB 203580, U0126 and NAM were purchased from Beyotime (Jiangsu, China). 
Lentiviral package and infection

pLVX system was used for lentivirus package. HEK293T cell was transfected by calcium phosphate according to the standard protocol. For stable transfection, cells were infected with lentiviruses and were screened by incubation with $1-2 \mu \mathrm{g} / \mathrm{ml}$ puromycin beginning at $48 \mathrm{~h}$ post-infection.

\section{Luciferase reporter assay}

GLS 3'-UTR was cloned from HeLa CDNA and inserted into pmirGLO. Luciferase plasmids were transfected into HeLa cell or MDA-MB-231 cell using Lipofectamine 2000 (Invitrogen). Cells were cultured with DMEM (no glucose) 24-h post-transfection. Luciferase assay was performed using the Dual Luciferase Assay System (Promega, Madison, WI, USA) after treatment for $36 \mathrm{~h}$. Relative luciferase activity was shown as the ratio to Renilla luciferase activity.

\section{Western blot and immunoprecipitation}

Cells were collected with IP lysis buffer (Beyotime, Jiangsu, China) and centrifuged at 12000 r.p.m. for $10 \mathrm{~min}$ at $4{ }^{\circ} \mathrm{C}$. The supernatant was incubated with appropriate antibodies in addition to protein $\mathrm{G}$ beads (Roche, Basel, Switzerland) overnight at $4{ }^{\circ} \mathrm{C}$. Immunoprecipitates were washed five times with PBS and resuspended in $60 \mu \mathrm{l}$ SDS loading buffer. Samples were separated by $10 \%$ SDS-PAGE and transferred to PVDF membrane (Millipore). Membranes were blocked with $5 \%$ non-fat milk or $5 \%$ BSA and then incubated with primary antibodies and secondary antibodies. Signals were visualized by chemiluminescence. Quantitative analysis was performed using Gelpro software.

\section{RT-PCR and quantitative PCR}

Total RNAs were isolated using the TRIzol reagent (Invitrogen) according to the manufacturer's instruction. Extracted RNAs were used for RT-PCR with the ReverTra Ace qPCR RT kit (TOYOBO, Osaka, Japan). Quantitative PCR was performed using Bio-Rad CFX96 Real-Time PCR Systems. Changes in gene expression were normalized to $18 \mathrm{~S}$. The primers were as follow: PDK1-F: 5'-TTACGCACAATACTTCCA-3' and PDK1-R: 5'-AGAGCCTTAAT GTAGATAACT-3'; PFK1-F: 5'-GGCTATGAACTGGATGTC-3' and PFK1-R: 5'-CCGAATCTGGAGTATTGG-3'; LDHA-F: 5'-GATGATGTCTTCCTTAGTGTT-3' and LDHA-R: 5'-AGTCAGAGTCACCTTCAC-3'; GLUT1-F: 5'-TATGTGGAGC AACTGTGT-3' and GLUT1-R: 5'-TGAAGTAGGTGAAGATGAAGA-3'; c-MYC-F: 5'-CCTGGTGCTCCATGAGGAGAC-3' and c-MYC-R: 5'-CAGACTCTGACCTITा GCCAGG-3'; 18S-F: 5'-AACTTTCGATGGTAGTCGCCG-3' and 18S-R: 5'-CCTTG GATGTGGTAGCCGTTT-3'.

\section{MTT Cell viability assay}

HeLa or MDA-MB-231 cells were seeded 2000 per well into 96-well plate. After being cultured for $24 \mathrm{~h}$ in a $\mathrm{CO}_{2}$ incubator, the cells were treated with DMEM (no glucose), DMEM (no glutamine) or DMEM (no glucose, no glutamine), respectively, for the indicated time. At different time points, $20 \mu \mathrm{l}$ of MTT (Sigma) solution $(5 \mathrm{mg} / \mathrm{ml})$ was added into each well. After incubation for $4 \mathrm{~h}$ at $37^{\circ} \mathrm{C}$, the medium was replaced with $150 \mu \mathrm{l}$ of DMSO, and the plate was allowed to shake on a plate shaker for $15 \mathrm{~min}$. Absorbance at 570 and $650 \mathrm{~nm}$ were measured using BioTek Synergy NEO (BioTek, Winooski, VT, USA). Each group was repeated for six times. Values are showed as fold changes versus 0-h group.

\section{Statistical analysis}

All the data were shown as mean \pm S.E.M. Comparison between two groups were performed by two-tailed student's $t$-test using GraphPad Prism (San Diego, CA, USA).

\section{ABBREVIATIONS}

GD, glucose deprivation; HIF1, hypoxia-inducible factor 1; GLUT1, glucose transporter 1; PFK, phosphofructokinase; PGK1, phosphoglycerate kinase 1 LDHA, lactate dehydrogenase A; PKM2, M2 isoform of pyruvate kinase $M$; PFKFB3, phosphofructokinase/fructose-2,6-bisphosphatase B3 gene; HK1, hexokinase 1; GLS, glutaminase; TIGAR, TP53-induced glycolysis and apoptosis regulator; $\mathrm{SCO} 2$, synthesis of cytochrome $\mathrm{C}$ oxidase 2; $\mathrm{CHX}$, cycloheximide; GSK3, glycogen synthase kinase 3.

\section{ACKNOWLEDGEMENTS}

This work was supported by National Natural Science Fund (31301064, 81372453), Natural Science Foundation of Shanghai (13ZR1446300), Young Scientists Program of Shanghai Institutes for Biological science, Youth Innovation Promotion Association, Chinese Academy of Sciences (2013KIP101), Shanghai Municipal Science and Technology Commission Fund (15431902800) and Chinese Ministry of Science and Technology (MOST) (2014CB964704).

\section{COMPETING INTERESTS}

The authors declare no conflict of interest.

\section{REFERENCES}

1 Warburg O. On respiratory impairment in cancer cells. Science 1956; 124: 269-270.

2 Koppenol WH, Bounds PL, Dang CV. Otto Warburg's contributions to current concepts of cancer metabolism. Nat Rev Cancer 2011; 11: 325-337.

3 Postovit LM, Adams MA, Lash GE, Heaton JP, Graham CH. Oxygen-mediated regulation of tumor cell invasiveness. Involvement of a nitric oxide signaling pathway. J Biol Chem 2002; 277: 35730-35737.

4 Krtolica A, Ludlow JW. Hypoxia arrests ovarian carcinoma cell cycle progression, but invasion is unaffected. Cancer Res 1996; 56: 1168-1173.

5 Yamamoto T, Seino Y, Fukumoto H, Koh G, Yano H, Inagaki N et al. Over-expression of facilitative glucose transporter genes in human cancer. Biochem Biophys Res Commun 1990; 170: 223-230.

6 Zancan P, Sola-Penna M, Furtado CM, Da Silva D. Differential expression of phosphofructokinase-1 isoforms correlates with the glycolytic efficiency of breast cancer cells. Mol Genet Metab 2010; 100: 372-378.

7 Wang J, Ying G, Jung Y, Lu J, Zhu J, Pienta KJ et al. Characterization of phosphoglycerate kinase-1 expression of stromal cells derived from tumor microenvironment in prostate cancer progression. Cancer Res 2010; 70: 471-480.

8 Luo W, Semenza GL. Emerging roles of PKM2 in cell metabolism and cancer progression. Trends Endocrinol Metab 2012; 23: 560-566.

9 Fantin VR, St-Pierre J, Leder P. Attenuation of LDH-A expression uncovers a link between glycolysis, mitochondrial physiology, and tumor maintenance. Cancer Cell 2006; 9: 425-434.

10 Christofk HR, Vander Heiden MG, Harris MH, Ramanathan A, Gerszten RE, Wei R et al. The M2 splice isoform of pyruvate kinase is important for cancer metabolism and tumour growth. Nature 2008; 452: 230-233.

11 Lv L, Li D, Zhao D, Lin R, Chu Y, Zhang $\mathrm{H}$ et al. Acetylation targets the M2 isoform of pyruvate kinase for degradation through chaperone-mediated autophagy and promotes tumor growth. Mol Cell 2011; 42: 719-730.

12 Vander Heiden MG, Cantley LC, Thompson CB. Understanding the Warburg effect: the metabolic requirements of cell proliferation. Science 2009; 324: 1029-1033.

13 Atsumi T, Chesney J, Metz C, Leng L, Donnelly S, Makita Z et al. High expression of inducible 6-phosphofructo-2-kinase/fructose-2,6-bisphosphatase (iPFK-2; PFKFB3) in human cancers. Cancer Res 2002; 62: 5881-5887.

14 Yalcin A, Telang S, Clem B, Chesney J. Regulation of glucose metabolism by 6-phosphofructo-2-kinase/fructose-2,6-bisphosphatases in cancer. Exp Mol Pathol 2009; 86: 174-179.

15 Arseneault R, Chien A, Newington JT, Rappon T, Harris R, Cumming RC. Attenuation of LDHA expression in cancer cells leads to redox-dependent alterations in cytoskeletal structure and cell migration. Cancer Lett 2013; 338: 255-266.

16 Le A, Cooper CR, Gouw AM, Dinavahi R, Maitra A, Deck LM et al. Inhibition of lactate dehydrogenase $A$ induces oxidative stress and inhibits tumor progression. Proc Natl Acad Sci USA 2010; 107: 2037-2042.

17 Gatenby RA, Gillies RJ. Why do cancers have high aerobic glycolysis? Nat Rev Cancer 2004; 4: 891-899.

18 Ward PS, Thompson CB. Metabolic reprogramming: a cancer hallmark even warburg did not anticipate. Cancer Cell 2012; 21: 297-308.

19 Kroemer G, Pouyssegur J. Tumor cell metabolism: cancer's Achilles' heel. Cancer Cell 2008; 13: 472-482.

20 Li F, Wang Y, Zeller Kl, Potter JJ, Wonsey DR, O'Donnell KA et al. Myc stimulates nuclearly encoded mitochondrial genes and mitochondrial biogenesis. Mol Cell Biol 2005; 25: 6225-6234.

21 Gao P, Tchernyshyov I, Chang TC, Lee YS, Kita K, Ochi T et al. c-Myc suppression of $\mathrm{miR}-23 \mathrm{a} / \mathrm{b}$ enhances mitochondrial glutaminase expression and glutamine metabolism. Nature 2009; 458: 762-765.

22 Le A, Lane AN, Hamaker M, Bose S, Gouw A, Barbi J et al. Glucose-independent glutamine metabolism via TCA cycling for proliferation and survival in B cells. Cell Metab 2012; 15: 110-121. 
23 Schwartzenberg-Bar-Yoseph F, Armoni M, Karnieli E. The tumor suppressor p53 down-regulates glucose transporters GLUT1 and GLUT4 gene expression. Cancer Res 2004; 64: 2627-2633.

24 Bensaad K, Tsuruta A, Selak MA, Vidal MN, Nakano K, Bartrons R et al. TIGAR, a p53-inducible regulator of glycolysis and apoptosis. Cell 2006; 126: 107-120.

25 Matoba S, Kang JG, Patino WD, Wragg A, Boehm M, Gavrilova $O$ et al. p53 regulates mitochondrial respiration. Science 2006; 312: 1650-1653.

26 Hsu PP, Sabatini DM. Cancer cell metabolism: Warburg and beyond. Cell 2008; 134: 703-707.

27 Ho FM, Lin WW, Chen BC, Chao CM, Yang CR, Lin LY et al. High glucose-induced apoptosis in human vascular endothelial cells is mediated through NF-kappaB and c-Jun NH2-terminal kinase pathway and prevented by PI3K/Akt/eNOS pathway. Cell Signal 2006; 18: 391-399.

28 Huang Q, Sheibani N. High glucose promotes retinal endothelial cell migration through activation of Src, PI3K/Akt1/eNOS, and ERKs. Am J Physiol Cell Physiol 2008; 295: C1647-C1657.

29 Kato K, Ogura T, Kishimoto A, Minegishi Y, Nakajima N, Miyazaki M et al. Critical roles of AMP-activated protein kinase in constitutive tolerance of cancer cells to nutrient deprivation and tumor formation. Oncogene 2002; 21: 6082-6090.

30 Laderoute KR, Amin K, Calaoagan JM, Knapp M, Le T, Orduna J et al. 5'-AMP-activated protein kinase (AMPK) is induced by low-oxygen and glucose deprivation conditions found in solid-tumor microenvironments. $\mathrm{Mol} \mathrm{Cell} \mathrm{BiO}$ 2006; 26: 5336-5347.

31 Sengupta S, Peterson TR, Sabatini DM. Regulation of the mTOR complex 1 pathway by nutrients, growth factors, and stress. Mol Cell 2010; 40: 310-322.

32 Feng $\mathrm{Z}$, Zhang $\mathrm{H}$, Levine $\mathrm{AJ}$, Jin $\mathrm{S}$. The coordinate regulation of the $\mathrm{p} 53$ and $\mathrm{mTOR}$ pathways in cells. Proc Natl Acad Sci USA 2005; 102: 8204-8209.

33 Schwer B, Eckersdorff M, Li Y, Silva JC, Fermin D, Kurtev MV et al. Calorie restriction alters mitochondrial protein acetylation. Aging Cell 2009; 8: 604-606.

34 Lin R, Tao R, Gao X, Li T, Zhou X, Guan KL et al. Acetylation stabilizes ATP-citrate lyase to promote lipid biosynthesis and tumor growth. Mol Cell 2013; 51: 506-518.

35 McBrian MA, Behbahan IS, Ferrari R, Su T, Huang TW, Li K et al. Histone acetylation regulates intracellular pH. Mol Cell 2013; 49: 310-321.

36 Dang CV, Le A, Gao P. MYC-induced cancer cell energy metabolism and therapeutic opportunities. Clin Cancer Res 2009; 15: 6479-6483.

37 Stoneley M, Paulin FE, Le Quesne JP, Chappell SA, Willis AE. C-Myc 5' untranslated region contains an internal ribosome entry segment. Oncogene 1998; 16: 423-428.

38 Kim SY, Herbst A, Tworkowski KA, Salghetti SE, Tansey WP. Skp2 regulates Myc protein stability and activity. Mol Cell 2003; 11: 1177-1188.

39 Popov N, Herold S, Llamazares M, Schulein C, Eilers M. Fbw7 and Usp28 regulate myc protein stability in response to DNA damage. Cell Cycle 2007; 6: 2327-2331.

40 von der Lehr N, Johansson S, Wu S, Bahram F, Castell A, Cetinkaya C et al. The F-box protein Skp2 participates in C-Myc proteosomal degradation and acts as a cofactor for c-Myc-regulated transcription. Mol Cell 2003; 11: 1189-1200.

41 Yada M, Hatakeyama S, Kamura T, Nishiyama M, Tsunematsu R, Imaki $\mathrm{H}$ et al. Phosphorylation-dependent degradation of c-Myc is mediated by the F-box protein Fbw7. EMBO J 2004; 23: 2116-2125.

42 Ying H, Kimmelman AC, Lyssiotis CA, Hua S, Chu GC, Fletcher-Sananikone E et al. Oncogenic Kras maintains pancreatic tumors through regulation of anabolic glucose metabolism. Cell 2012; 149: 656-670.

43 Cheung EC, Vousden $\mathrm{KH}$. The role of p53 in glucose metabolism. Curr Opin Cell Biol 2010; 22: 186-191.

44 Jhawer M, Goel S, Wilson AJ, Montagna C, Ling YH, Byun DS et al. PIK3CA mutation/PTEN expression status predicts response of colon cancer cells to the epidermal growth factor receptor inhibitor cetuximab. Cancer Res 2008; 68: 1953-1961.

45 Weigelt B, Warne PH, Downward J. PIK3CA mutation, but not PTEN loss of function, determines the sensitivity of breast cancer cells to mTOR inhibitory drugs. Oncogene 2011; 30: 3222-3233.

46 Ahnen DJ, Feigl P, Quan G, Fenoglio-Preiser C, Lovato LC, Bunn PA Jr. et al. Ki-ras mutation and p53 overexpression predict the clinical behavior of colorectal cancer: a Southwest Oncology Group study. Cancer Res 1998; 58: 1149-1158.

47 Ichikawa $Y$, Nishida M, Suzuki H, Yoshida S, Tsunoda H, Kubo T et al. Mutation of $\mathrm{K}$-ras protooncogene is associated with histological subtypes in human mucinous ovarian tumors. Cancer Res 1994; 54: 33-35.

48 Hengstermann A, Linares LK, Ciechanover A, Whitaker NJ, Scheffner M. Complete switch from Mdm2 to human papillomavirus E6-mediated degradation of p53 in cervical cancer cells. Proc Natl Acad Sci USA 2001; 98: 1218-1223.

49 Cheung WD, Hart GW. AMP-activated protein kinase and p38 MAPK activate O-GlcNAcylation of neuronal proteins during glucose deprivation. $J$ Biol Chem 2008; 283: 13009-13020.
50 Majewski N, Nogueira V, Robey RB, Hay N. Akt inhibits apoptosis downstream of BID cleavage via a glucose-dependent mechanism involving mitochondrial hexokinases. Mol Cell Biol 2004; 24: 730-740.

51 Yang L, Guo W, Zhang Q, Li H, Liu X, Yang Y et al. Crosstalk between Raf/MEK/ERK and PI3K/AKT in suppression of Bax conformational change by Grp75 under glucose deprivation conditions. J Mol Biol 2011; 414: 654-666.

52 Liang J, Shao SH, Xu ZX, Hennessy B, Ding Z, Larrea M et al. The energy sensing LKB1-AMPK pathway regulates p27(kip1) phosphorylation mediating the decision to enter autophagy or apoptosis. Nat Cell Biol 2007; 9: 218-224.

53 Cantley LC. The phosphoinositide 3-kinase pathway. Science 2002; 296: 1655-1657.

54 Kaliman P, Canicio J, Shepherd PR, Beeton CA, Testar X, Palacin M et al. Insulin-like growth factors require phosphatidylinositol 3-kinase to signal myogenesis: dominant negative p85 expression blocks differentiation of L6E9 muscle cells. Mol Endocrinol 1998; 12: 66-77.

55 Burgering BM, Coffer PJ. Protein kinase B (c-Akt) in phosphatidylinositol-3-OH kinase signal transduction. Nature 1995; 376: 599-602.

56 Gregory MA, Qi Y, Hann SR. Phosphorylation by glycogen synthase kinase-3 controls c-myc proteolysis and subnuclear localization. J Biol Chem 2003; 278: 51606-51612.

57 Diehl JA, Cheng M, Roussel MF, Sherr CJ. Glycogen synthase kinase-3beta regulates cyclin D1 proteolysis and subcellular localization. Genes Dev 1998; 12: 3499-3511.

58 Kotani K, Ogawa W, Hino Y, Kitamura T, Ueno H, Sano W et al. Dominant negative forms of Akt (protein kinase B) and atypical protein kinase Clambda do not prevent insulin inhibition of phosphoenolpyruvate carboxykinase gene transcription. J Biol Chem 1999; 274: 21305-21312.

59 Cohen HY, Miller C, Bitterman KJ, Wall NR, Hekking B, Kessler B et al. Calorie restriction promotes mammalian cell survival by inducing the SIRT1 deacetylase. Science 2004; 305: 390-392.

60 Shim H, Chun YS, Lewis BC, Dang CV. A unique glucose-dependent apoptotic pathway induced by c-Myc. Proc Natl Acad Sci USA 1998; 95: 1511-1516.

61 Okuyama H, Endo H, Akashika T, Kato K, Inoue M. Downregulation of c-MYC protein levels contributes to cancer cell survival under dual deficiency of oxygen and glucose. Cancer Res 2010; 70: 10213-10223.

62 Yuneva M, Zamboni N, Oefner P, Sachidanandam R, Lazebnik Y. Deficiency in glutamine but not glucose induces MYC-dependent apoptosis in human cells. J Cell Biol 2007; 178: 93-105.

63 Kato GJ, Lee WM, Chen LL, Dang CV. Max: functional domains and interaction with c-Myc. Genes Dev 1992; 6: 81-92.

64 Dang CV. Rethinking the Warburg effect with Myc micromanaging glutamine metabolism. Cancer Res 2010; 70: 859-862.

65 Liu W, Le A, Hancock C, Lane AN, Dang CV, Fan TW et al. Reprogramming of proline and glutamine metabolism contributes to the proliferative and metabolic responses regulated by oncogenic transcription factor c-MYC. Proc Natl Acad Sci USA 2012; 109: 8983-8988.

66 Denko NC. Hypoxia, HIF1 and glucose metabolism in the solid tumour. Nat Rev Cancer 2008; 8: 705-713.

67 Green DR, Chipuk JE. p53 and metabolism: Inside the TIGAR. Cell 2006; 126: 30-32.

68 Blackburn RV, Spitz DR, Liu X, Galoforo SS, Sim JE, Ridnour LA et al. Metabolic oxidative stress activates signal transduction and gene expression during glucose deprivation in human tumor cells. Free Radic Biol Med 1999; 26: 419-430.

69 Hann SR. Role of post-translational modifications in regulating c-Myc proteolysis, transcriptional activity and biological function. Semin Cancer Biol 2006; 16: 288-302.

70 Lee YJ, Galoforo SS, Berns CM, Chen JC, Davis BH, Sim JE et al. Glucose deprivation-induced cytotoxicity and alterations in mitogen-activated protein kinase activation are mediated by oxidative stress in multidrug-resistant human breast carcinoma cells. J Biol Chem 1998; 273: 5294-5299.

71 Haga N, Saito S, Tsukumo Y, Sakurai J, Furuno A, Tsuruo T et al. Mitochondria regulate the unfolded protein response leading to cancer cell survival under glucose deprivation conditions. Cancer Sci 2010; 101: 1125-1132.

72 Griguer CE, Oliva CR, Gillespie GY. Glucose metabolism heterogeneity in human and mouse malignant glioma cell lines. J Neurooncol 2005; 74: 123-133.

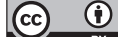

This work is licensed under a Creative Commons Attribution 4.0 International License. The images or other third party material in this article are included in the article's Creative Commons license, unless indicated otherwise in the credit line; if the material is not included under the Creative Commons license, users will need to obtain permission from the license holder to reproduce the material. To view a copy of this license, visit http://creativecommons.org/licenses/ by/4.0/ 